\title{
Reeleição parlamentar: reflexões metodológicas e análise do caso da Câmara de Vereadores de Pelotas (1976-2004)
}

\author{
Alvaro Barreto \\ Instituto de Sociologia e Política \\ Universidade Federal de Pelotas
}

\begin{abstract}
Resumo: O artigo aborda a problemática da reeleição e de outras variáveis a ela relacionadas, como desistência, reapresentação e renovação. Inicialmente, discute aspectos conceituais e metodológicos. Depois, centra-se no caso da Câmara de Vereadores de Pelotas (RS), nos pleitos de 1982 a 2004, com o objetivo de identificar padrões e tendências que se mantêm ou se modificam no tempo, bem como realizar uma análise compreensiva dos significados políticos e institucionais desses fenômenos.
\end{abstract}

Palavras-chaves: reeleição; renovação parlamentar; sistema político; Câmara de Vereadores

Abstract: This paper deals with the reelection issue and other variables related to it, such as desistance of running, running again and parliamentary renewal. Initially, the conceptual and methodological aspects of this line of inquiry. Later, it is centered in the case of the Chamber of Councilmen of Pelotas (RS), in the elections of 1982 up to 2004, with the objective of identifying patterns and trends that remain or that are modified along the time, as well as carrying through a comprehensive analysis of the political and institutional meanings of these phenomena.

Keywords: reelection; parliamentary renewal; political system; local Chamber

*O trabalho contou com a colaboração de Tiago Bessa, especialista em Política pelo ISP/UFPel. 


\section{Introdução}

Este artigo aborda a problemática da reeleição e de outras variáveis a ela relacionadas, como desistência, reapresentação e renovação. O caso analisado é a Câmara de Vereadores de Pelotas (RS) entre os pleitos de 1982 a 2004, e como objetivos identificar padrões e tendências no tempo, tem como realizar uma análise compreensiva dos significados políticos e institucionais desses fenômenos, o que implica observar como determinadas características do sistema eleitoral podem influenciar essas variáveis e serem por elas influenciadas.

No Brasil, essa linha de pesquisa vem sendo desenvolvida desde a década de 1970. Autores como Santos (1971, 1987, 1997, 2002, 2003), Fleischer (1980, 1981), Soares e D’Araújo (1993), Mainwaring (1991, 2001), Novaes (1994), Grohmann (1995), Figueiredo e Limongi (1996), Schmitt (1999), Carneiro e Schmitt (2001), Pereira e Rennó (2001), Araújo (2002), Leoni, Pereira e Rennó (2003), Botero e Rennó (2007) produziram importantes discussões metodológicas, estudos aplicados e reflexões sobre esta problemática, que estão incorporadas a este artigo.

O texto está estruturado em três seções. A primeira apresenta e discute as questões metodológicas relacionadas às categorias de análise, em especial "renovação" e "reeleição". A segunda traz os dados empíricos relativos à Câmara de Vereadores de Pelotas entre 1976 e 2004, necessários para a identificação dos fenômenos nos seis pleitos a serem observados (1982, 1988, 1992, 1996, 2000 e 2004). A terceira e última seção relaciona essas informações com elementos do sistema eleitoral e com o repertório de interpretações presentes na bibliografia.

\section{Aspectos metodológicos}

Os estudos sobre a questão giram em torno de quatro categorias relacionadas entre si, mas passíveis de serem abordadas de modo independente: "renovação", "desistência", "reapresentação" e "reeleição".

A variável "renovação" tem sido concebida como: "mudança de pessoas na representação" (SANTOS, 1971, p.20), "mudança na composição dos membros de um parlamento entre duas legislaturas" (ARAúJO, 2002, p.11), "resultado de um processo em que novos candidatos e novos membros passam a fazer parte de um corpo legislativo, ocupando os lugares que, por diversas razões, não foram preenchidos pelos seus antigos ocupantes" (ARAÚJO, 2002, p.19), ou ainda como "a presença de novos representantes 
dentro de um corpo legislativo ou, o que é o mesmo, a saída (por desistência ou por derrota) de antigos"(SCHMITT, 1999, p. 128) ${ }^{1}$

Há uma sutil divisão na bibliografia quanto à condição de "novo". Fleischer distingue os "calouros", aqueles que nunca ocuparam aquele cargo, nem como suplente dos "novatos", os que não estavam na legislatura anterior, mas exerceram o mandato, como titular ou suplente, em legislaturas anteriores (FLEISCHER, 1980, p58). Na tese do autor, a renovação será mais efetiva se houver maior número de "calouros" do que de "novatos". Dois exemplos recentes ilustram a questão: Fernando Collor e Ibsen Pinheiro, que não freqüentaram o Congresso Nacional nas últimas legislaturas seriam considerados "novos", embora, na distinção de Fleischer, deveriam ser classificados como "novatos". Para além de uma filigrana, a distinção é útil para avaliar situações como as citadas, dado que os significados políticos de uma "renovação" como esta devem ser analisados, e a peculiaridade dos casos de Collor e Ibsen pode desaparecer se a classificação for simplesmente a de "novos".

Diretamente vinculadas à "renovação" estão as categorias de "desistência"2 (ou "não candidatura") e "reapresentação" (também chamada de "recandidatura" ou simplesmente de "candidatura"), visto serem as duas faces de uma mesma moeda. A "desistência" indica os parlamentares que, por um motivo ou outro - e estes merecem análise específica, deixaram de concorrer. A "reapresentação", ao inverso, aponta os parlamentares que buscaram subseqüentemente um novo mandato para o mesmo cargo. A relação que se estabelece é quanto maior a desistência, maior a renovação, ou seja, necessariamente os cargos serão ocupados por "novos" detentores do mandato (calouros ou novatos).

Segundo Santos (1971, p.21; 2002, p.15), o índice de parlamentares que desistem implica a "renovação compulsória", o percentual de mudança na composição da legislatura que vai se processar independentemente do fator eleitoral, mantido o mesmo número de cadeiras. Ele é o produto da divisão do número de desistentes pelo total de membros da legislatura. O inverso desse tipo de renovação é a "taxa de reapresentação", índice de parlamentares que se candidataram para novo mandato, calculado pela divisão do número de recandidaturas pelo total de parlamentares. A taxa de representação é equivalente ao que Figueiredo e Limongi (1996) chamam de "taxa de candidatura".

\footnotetext{
${ }^{1} \mathrm{O}$ termo está consagrado pelo uso e será repetido neste artigo, porém, incorpora uma carga valorativa dissociada do tipo de análise que o subsidia, visto que evoca a idéia de que a "renovação" é positiva ou desejável, ao vincular-se ao universo simbólico do "novo", do "jovem" e, por oposição, do "antigo" e do que precisa ser modificado. Entretanto, se o fenômeno é simplesmente a "mudança na composição dos membros de um parlamento entre duas legislaturas", a denominação nada deveria indicar sobre a efetiva ou projetada qualidade dessa mudança.

2É outra denominação que corre o risco de se mostrar imprecisa, pois, dentre as razões para que um parlamentar não concorra, podem estar algumas que não correspondem integralmente à idéia suscitada pelo termo "desistência", tais como morte, impedimento legal, não aprovação pelo partido.
} 
No caso da "reapresentação", é preciso considerar o sucesso ou o insucesso do candidato. A "reeleição" é conceituada como o "grau de recondução, numa nova legislatura, de parlamentares provenientes da(s) anterior(es)" (SCHMITT, 1999, p.128) ou a freqüência com que os parlamentares, tendo se reapresentado, obtiveram um novo mandato (ARAÚJO, 20002, p.60). Mede-se pela "taxa de reeleição", obtida por meio da divisão do número de sucessos pelo número total de reapresentações, sendo correspondente ao que Santos (1997, p. 20; 2002, p. 16) chama de "conservação".

O inverso delas é a "renovação líquida ou deliberada", concebida por Santos (2002, p.15) como o resultado da divisão do número dos que não foram eleitos (também chamados de "derrotados") pelo total dos que se reapresentaram. Soares e D'araújo (1993, p.188) especulam ser esta a forma mais adequada de calcular a "renovação", visto que devem ser excluídos os que não se recandidataram ou que se candidataram a outros cargos. Pode-se considerar, ainda, outro tipo de "renovação", chamada por Santos (1971, p.20) de "vegetativa", correspondente ao acréscimo de cadeiras legislativas, e que, a exemplo da "compulsória", vai ocorrer independentemente do resultado eleitoral ${ }^{3}$.

Finalmente, Santos (1971) apresenta a "taxa de renovação bruta", que nada mais é do que a reunião dos índices anteriores: advém da junção dos parlamentares que desistiram e dos que não se reelegeram com as novas cadeiras legislativas (se houver). A operacionalização é realizada pela soma dessas freqüências, dividida pelo total de vagas legislativas.

Sobre este tema, Fleischer fala em "taxa de retorno ou permanência", concebida como "a permanência de deputados de uma legislatura para outra; a estabilidade ou, se quiser, o imobilismo" (FLEISCHER, 1980, p.58) ${ }^{4}$. Schmitt (1999, p.133) e Araújo (2002, p.17) afirmam que esta taxa é o inverso da "renovação líquida ou deliberada" e deve ser calculada sobre o total de recandidaturas. Face a isso, Araújo propõe a variável "reeleição pura", cuja taxa é o produto da divisão do número de reeleições pelo total de cadeiras do parlamento (ARAÚJO, 2002, p.61). Todavia, consideramos que a "taxa de retorno ou permanência" espelha melhor a definição estabelecida por Fleischer se for calculada sobre o total de cadeiras, o que a torna equivalente à "taxa de renovação pura". Nesse caso, ela seria o inverso da "renovação bruta" e não da "líquida".

\footnotetext{
${ }^{3}$ Posteriormente, Santos (1997; 2002) incorporou uma fórmula em que é possível ponderar o acréscimo no número de cadeiras. Schmitt (1999) e Araújo (2002) desconsideram a "renovação vegetativa". Entretanto, nenhum dos autores consultados faz referências à redução no número de cadeiras do parlamento e ao impacto que este fato causa no modo de calcular e de conceber a "renovação" ou a "reeleição", o que será comentado na seqüência deste artigo.

${ }^{4}$ Os termos utilizados por Soares e Fleischer para caracterizarem a permanência (conservação, imobilismo), ao serem cotejados com o universo simbólico da "renovação", corroboram o que foi indicado na nota 1 .
} 
Até aqui, o artigo procurou descrever como cada termo tem sido concebido e apresentar as definições que subsidiam o modo como devem ser calculados. No entanto, há uma série de questões metodológicas relacionadas a estes aspectos que afetarão diretamente os índices a serem obtidos e, conseqüentemente, as análises empreendidas a partir deles. Uma das dificuldades é como operacionalizar as categorias. Mais do que simples escolhas, elas têm implicações empíricas e teóricas não desprezíveis, como enfatizam Soares e D’Araújo (1993, p. 187).

Os autores que se preocupam prioritariamente com a questão da "renovação", como Santos (1971), Fleischer (1980, 1981) e Araújo (2002), tendem a considerar somente os parlamentares eleitos e a desprezar os suplentes que tenham assumido o mandato, independentemente da condição (provisória ou permanente). Entendemos tal decisão, pois ela dimensiona com mais propriedade as diferenças entre as nominatas de duas legislaturas subseqüentes, consideradas em razão dos resultados eleitorais ${ }^{5}$. Enfim, ela identifica, com precisão, as mudanças ocorridas na composição do parlamento entre um pleito e outro, isto é, no intervalo de quatro anos (ou seis, dependendo da legislatura considerada).

No entanto, esta decisão corre o risco de não conseguir radiografar com a mesma precisão o cenário em que se processa o pleito que servirá de parâmetro para medir a "renovação". Isso porque muitos dos eleitos na disputa imediatamente anterior deixaram o mandato, por razões diversas, tendo sido substituídos definitivamente por suplentes. Quando da nova eleição, estes que assumiram o cargo são percebidos pelo eleitorado como parlamentares em busca da reeleição. Este aspecto questiona Schmitt (1999, p. 135-6) e Araújo (2002, p. 62), quando declaram que a opção adotada por eles implica supor que, no momento desse novo pleito, o eleitorado é capaz de identificar quais candidatos integravam a relação dos eleitos no pleito anterior. Ao invés de "enviesar" a amostra, como alegam os autores, esta pode ser uma decisão que, em nome de um padrão uniforme de análise e de um trabalho de campo de mais fácil execução, adota um critério válido, porém contraditório em relação aos fatos (desconsidera a efetividade das substituições na composição do legislativo), e que nitidamente abre mão de observar a diversidade de situações da realidade política concreta.

\footnotetext{
${ }^{5}$ Os autores sempre se referem ao resultado eleitoral, e não a quem assumiu o mandato, logo deixam de comentar a possibilidade de que a relação de eleitos seja modificada entre o pleito e posse da legislatura.
} 
Embora dispense esse tipo de abordagem, Schmitt reconhece sua importância: "o destino dos 152 deputados federais eleitos quatro anos antes que não concorreram à própria reeleição pode vincular-se a diversos fatores. Uma investigação empírica desses casos produziria certamente resultados bastante interessantes" (SCHMITT, 1999, p.139). A afirmação é repetida por Araújo (2002, p.70).

Além disso, medir a "renovação" a partir do conjunto de parlamentares que inauguraram a legislatura, sem admitir substituições ao longo do mandato, amplia a tendência de que as "taxas de renovação compulsória" e "bruta" sejam mais altas. Afinal, qualquer impedimento dos titulares que os faça desistir de tentar a reeleição implica o ingresso de novos nomes na legislatura seguinte. Na prática, dependendo das circunstâncias, essas duas taxas registrarão a mudança na nominata do parlamento ocorrida algum tempo antes (especialmente no caso de morte, impedimento legal ou renúncia) e que já pode ter sido "absorvida" pelo parlamento, pelas instituições partidárias e pelo eleitorado.

Em razão dessa dificuldade, o cálculo da "taxa de reeleição" é aquele que melhor exprime a "renovação" ao abarcar somente aqueles parlamentares que buscaram um novo mandato. Todavia, a orientação metodológica criticada traz implicações também para o resultado dessa taxa, pois amplia a possibilidade de que ela seja menor, visto que exclui da observação os suplentes que se tornaram titulares, reapresentaram-se e obtiveram um novo mandato.

Se a preocupação maior do pesquisador for dimensionar o grau de "reeleição", a incorporação dos suplentes que assumiram definitivamente o cargo ao longo da legislatura pode ser uma escolha mais coerente, dado ser mais provável que estes busquem obter um novo mandato, ainda mais se assumiram o cargo na metade da legislatura ${ }^{6}$, e possam se servir da condição de parlamentar para viabilizar este intento. Como foi afirmado anteriormente, é bastante razoável que quem ficou como suplente na eleição anterior e assumiu o cargo durante a legislatura seja percebido pelo eleitorado, ou tente ser notado por ele como "parlamentar", muito mais do que o eleito originalmente e que, ao longo do tempo, assumiu outro cargo (eletivo ou não), renunciou, morreu ou sofreu algum tipo de impedimento legal.

Leoni, Pereira e Rennó incluíram tanto os deputados eleitos quanto os suplentes que exerceram o mandato, mesmo que por algum tempo. A escolha se impôs por causa do objetivo de "identificar as decisões de carreira enfrentadas pelos deputados federais brasileiros no final de seus mandatos" (LEONI, PEREIRA e RENNÓ, 2003, p.47) e da constatação de que "uma vez que todos os membros de nossa amostra tiveram uma chance de exercer mandato por algum período de tempo e usar suas prerrogativas de deputados federais, eles foram incluídos na amostra analisada" (LEONI,

6 O calendário eleitoral estabelecido a partir de 1986-1988 amplia a possibilidade de mudanças em meio às legislaturas ao alternar, a cada dois anos, pleitos municipais e estaduais ou nacionais. 
PEREIRA e RENNÓ, 2003, p.45). Pelas mesmas razões, foram excluídos todos aqueles que não puderam ou não precisaram tomar essa decisão (no caso específico quem morreu durante o mandato, foi eleito prefeito ou vereador, nomeado para o Supremo Tribunal de Contas ou expulso da Câmara de Deputados).

Apenas para demonstrar como as decisões metodológicas são particularmente difíceis neste campo, não se deve deixar de considerar a existência de um parlamentar que tenha renunciado ao mandato durante a legislatura para se tornar prefeito ou vice (no caso de deputado federal), deputado estadual ou federal (no caso de vereador) ${ }^{7}$, e no pleito seguinte venha a se apresentar ao mesmo cargo. Nesse caso em que houve a renúncia formal, ele é um parlamentar que pleiteia a reeleição, como considerariam os que não contemplam substituições, ou um concorrente que busca um mandato novo, como indica o critério aqui sugerido? $\mathrm{E}$, como face da mesma moeda, o suplente que o sucedeu é um parlamentar em busca da reeleição ou alguém que busca um mandato novo?

Se ambos forem considerados "candidatos à reeleição", evidentemente há mais "parlamentares" do que "cadeiras" na mesma legislatura. Se apenas um for classificado como titular do cargo, e a escolha recair sobre quem havia sido eleito, evidentemente o critério apresentado no parágrafo anterior é falho ou incompleto. Se o titular for o suplente que veio a assumir o cargo e aquele que renunciou ao mandato tornar-se um pretendente ao mesmo cargo resta a dificuldade de dimensionar em um critério quantitativo como o eleitor percebe o fato, ainda mais se forem incluídas variáveis como o período em que isso se deu, as personalidades e as trajetórias políticas de cada um, assim como as legendas a que estavam vinculados quando da eleição anterior e quando da disputa presente. Enfim, dependendo do sucesso ou insucesso eleitoral de cada um, e da quantidade de casos a serem ponderados, haverá variações significativas nos índices de "reeleição"8.

Situação semelhante é a do parlamentar que se licencia para ocupar um cargo político-administrativo, sendo substituído por um suplente em caráter provisório, mas não retorna ao posto. Nesse caso, a licença significou, na prática, que ele nunca mais retomou o mandato, o suplente foi o "titular" e, nessa condição, reapresentou-se (ou eventualmente não se reapresentou). Como muitas dessas

\footnotetext{
${ }^{7}$ Outras combinações são possíveis, embora menos prováveis, como por exemplo: um deputado federal ou estadual tornar-se vereador ou um vereador tornar-se senador, governador ou vice.

¿Leoni, Pereira e Rennó (2003) não tiveram dúvidas, consideraram titulares e suplentes, de modo que há mais "deputados" do que vagas. Entretanto, entendemos tal decisão, visto que os autores deixam bem claro que não estão preocupados em medir o sucesso ou o fracasso nas recandidaturas, e sim dimensionar as escolhas que os parlamentares fazem para a continuidade da carreira política.
} 
licenças ocorrem no início da legislatura em razão da nomeação para ministérios ou secretarias, o suplente foi "parlamentar" na maior parte o período?.

Estudos como os referenciados acima, voltados basicamente ao Congresso Nacional, podem não ter percebido esses desafios metodológicos, visto a grande quantidade de dados e de situações a serem analisadas. Eles também podem conscientemente tê-los desprezado, diante da grandiosidade do empreendimento e das implicações que trariam o procedimento de analisar cada situação em particular. Finalmente, é possível que os tenham dispensado em razão do reduzido peso relativo que cada caso teria sobre o total das incidências e a identificação dos padrões.

As circunstâncias que envolvem uma pesquisa como esta, centrada em uma Câmara municipal, ao longo de sete eleições, o que significa analisar 126 cadeiras apenas uma legislatura da Câmara de Deputados envolve cinco vezes mais vagas -, ao mesmo tempo em que ajudam a evidenciar as implicações de tais desafios metodológicos, tornam-na mais sensível às dificuldades e às distorções que podem originar.

Empreendemos um estudo quantitativo idêntico aos precedentes, mas que se beneficiou das circunstâncias da menor amplitude do trabalho empírico para enfrentar os impasses metodológicos referenciados. Desse modo, foi construído registro de incidências atento à diversidade de situações para que os dados quantitativos conseguissem indicar com mais precisão as conjunturas políticas concretas, ao invés de serem um simples enquadramento em categorias previamente estabelecidas e que acabavam por submeter a dinamicidade dos fatos a um padrão correto, contudo não correspondente.

Observaram-se as situações particulares com vistas a definir quais das substituições de "titulares" ocorridas durante a legislatura seriam consideradas relevantes e, por conseqüência, os "suplentes" que passariam a ser classificados como "titulares", bem como as circunstâncias do sucesso ou do fracasso na tentativa de reeleição. Para deixar claro o impacto desses critérios de organização dos dados, nas primeiras tabelas (relativas à "desistência") são apresentados o modelo, os demais trabalhos e as peculiaridades produzidas pelo modo desenvolvido no presente artigo, são também destacadas as diferenças existentes entre elas.

\footnotetext{
${ }^{9}$ Reconhecemos, no entanto, que um exemplo como este é exceção. Em caso de licenças, a situação mais comum é a de que o titular abandone o cargo para o qual foi nomeado e retome o mandato, quando do prazo legal de desincompatibilização, pois ambiciona manter um cargo eletivo (o mesmo ou outro). Nessa situação, ele deve ser considerado o titular e a eventual desistência ou reapresentação ser contabilizada conforme a opção dele, apesar de o suplente ter exercido o mandato a maior parte do tempo.
} 
BARRETO, A. Reeleição parlamentar: reflexões metodológicas e análise...

\section{Dados empíricos}

Esta seção traz os dados empíricos relativos aos vereadores de Pelotas, obtidos pelo Grupo de Pesquisa "Sistema político - eleições, partidos e relações Executivo-Legislativo" (Instituto de Sociologia e Política da Universidade Federal de Pelotas), através do projeto "Mapeamento do sistema partidário pelotense (1982. 2004)". As fontes foram a Justiça Eleitoral e o jornal "Diário Popular".

As informações abarcam um total de sete pleitos (1976, 1982, 1988, 1992, 1996, 2000 e 2004), seis legislaturas completas: 1977-1983, 1983-1988, 1989. 1992, 1993-1996, 1997-2000 e 2001-2004, mais a formação inicial do período 2005-2008, ainda em andamento. O pleito de 1976 e a legislatura 1977-1983 servem como referência para as comparações realizadas conforme pares de disputas sucessivas, significando seis medições (1982-1976, 1988-1982, 1992. 1988, 1996-1992, 2000-1996, 2004-2000).

Para facilitar a comparação, definiu-se que a filiação partidária dos vereadores na eleição de 1982 seria válida para o pleito de 1976, sem levar em consideração que essas legendas surgiram depois da reforma partidária de 1979, a mesma que extinguiu aquelas existentes quando da disputa de 1976 (Arena e MDB). Isso significa dizer que, a rigor, a comparação entre as filiações é indevida, pois as eleições ocorreram em dois sistemas partidários distintos. Por outro lado, a diferença não é tão drástica quanto se pode pensar: todos os vereadores eleitos pela Arena em 1976 concorreram pelo PDS em 1982, e todos os que haviam sido eleitos pelo MDB disputaram pelo PMDB, com exceção de um, que se filiou ao PDT.

A Câmara foi composta por 21 cadeiras até o pleito mais recente, quando houve a redução para 15 vagas. Como será evidenciado, essa mudança traz implicações significativas para alguns dos cálculos.

Por fim, todos os eleitos assumiram o mandato; logo, não há discrepância entre o resultado das urnas e a composição inicial das legislaturas. Contudo, o trabalho contemplou cinco substituições ocorridas ao longo das legislaturas, a partir dos critérios anteriormente apresentados. Uma troca ocorreu por causa de morte $^{10}$ e outras três porque o titular renunciou ao mandato para tornar-se deputado ${ }^{11}$. A quinta é mais complexa, mas passível de entendimento, tendo envolvido Pedro Machado Filho e Raimundo Vieira da Cunha, ambos do PMDB. Em 1982, Machado Filho, um político em fim de carreira e que ocupava a presidência

\footnotetext{
${ }^{10} \mathrm{O}$ vereador Carlos De Bem morreu no período inicial do mandato, durante a legislatura 1983-1988 e foi substituído por Mário Prietsch.

${ }^{11}$ Dois tornaram-se deputados estaduais: Tufy Salomão (legislatura 1983-1988) e Cecília Hypólito (1997. 2000), sendo substituídos por, respectivamente, Álvaro Ratto e Miriam Marroni. Outro assumiu o cargo de deputado federal, Nelson Härter (legislatura 1997-2000), cuja vaga passou a Jesus David.
} 
da Câmara local, renunciou ao mandato para assumir prefeitura, pois o titular e o vice tiveram de abrir mão de seus cargos para poderem concorrer a cargo de deputado no pleito daquele ano. A renúncia do vereador, que era do partido do prefeito, compôs uma negociação que objetivava manter o PMDB no comando do município e na qual estava incluída uma reforma do secretariado, realizada para acomodar os interesses dos diversos candidatos às eleições de 1982. Nesse arranjo, foi garantida a permanência de Raimundo Vieira da Cunha até o final do mandato. Ele havia ficado como segundo suplente em 1976, porém ocupou o cargo durante toda a legislatura em razão do aproveitamento de colegas de bancada como secretários municipais. Foi na condição de vereador que ele buscou (e conseguiu) a reeleição (ARAÚJO, A., 2006). Os cinco suplentes levados à condição de vereador tiveram representação.

\section{1 - Desistências e reapresentações}

A Tabela 1 reúne os dados relativos aos 21 vereadores que iniciaram cada uma das legislaturas do período 1977-2004, sem considerar substituições. Reproduz, portanto, o critério utilizado por Schmitt (1999) e Araújo (2002), criticado anteriormente. A Tabela 2 sistematiza as informações a partir da aplicação da decisão metodológica de considerar as substituições definitivas ocorridas durante a legislatura.

Tabela 1. Decisão tomada pelos vereadores de Pelotas que iniciaram a legislatura em relação à eleição seguinte (1982-2004)

\begin{tabular}{|c|c|c|c|c|c|}
\cline { 2 - 6 } \multicolumn{1}{c|}{} & Vereadores & Desistência & Representação & $\begin{array}{c}\% \\
\text { Desistência }\end{array}$ & $\begin{array}{c}\% \\
\text { Reapresentação }\end{array}$ \\
\hline $\mathbf{1 9 8 2}$ & 21 & 4 & 17 & 19,0 & 81,0 \\
\hline $\mathbf{1 9 8 8}$ & 21 & 5 & 16 & 23,8 & 76,2 \\
\hline $\mathbf{1 9 9 2}$ & 21 & 4 & 17 & 19,0 & 81,0 \\
\hline $\mathbf{1 9 9 6}$ & 21 & 4 & 17 & 19,0 & 81,0 \\
\hline $\mathbf{2 0 0 0}$ & 21 & 4 & 17 & 19,0 & 81,0 \\
\hline $\mathbf{2 0 0 4}$ & 21 & 2 & 19 & 9,5 & 90,5 \\
\hline Total & $\mathbf{1 2 6}$ & $\mathbf{2 3}$ & $\mathbf{1 0 3}$ & $\mathbf{1 8 , 3}$ & $\mathbf{8 1 , 7}$ \\
\hline
\end{tabular}

Fonte: Projeto "Mapeamento do sistema partidário pelotense (1982-2004)" - Grupo de Pesquisa "Sistema político - eleições, partidos e relações Executivo-Legislativo" (Instituto de Sociologia e Política da Universidade Federal de Pelotas). 
Tabela 2. Decisão tomada pelos vereadores de Pelotas que concluíram o mandato em relação à eleição seguinte (1982-2004)

\begin{tabular}{|c|c|c|c|c|c|}
\cline { 2 - 6 } \multicolumn{1}{c|}{} & $\begin{array}{l}\text { Número de } \\
\text { Vereadores }\end{array}$ & $\begin{array}{l}\text { Número de } \\
\text { Desistência }\end{array}$ & $\begin{array}{c}\text { Número de } \\
\text { Reapresentação }\end{array}$ & $\begin{array}{c}\% \\
\text { Desistência }\end{array}$ & $\begin{array}{c}\% \\
\text { Reapresentação }\end{array}$ \\
\hline $\mathbf{1 9 8 2}$ & 21 & 3 & 18 & 14,3 & 85,7 \\
\hline $\mathbf{1 9 8 8}$ & 21 & 3 & 18 & 14,3 & 85,7 \\
\hline $\mathbf{1 9 9 2}$ & 21 & 4 & 17 & 19,0 & 81,0 \\
\hline $\mathbf{1 9 9 6}$ & 21 & 4 & 17 & 19,0 & 81,0 \\
\hline $\mathbf{2 0 0 0}$ & 21 & 2 & 19 & 9,5 & 90,5 \\
\hline $\mathbf{2 0 0 4}$ & 21 & 2 & 19 & 9,5 & 90,5 \\
\hline Total & $\mathbf{1 2 6}$ & $\mathbf{1 8}$ & $\mathbf{1 0 8}$ & $\mathbf{1 4 , 3}$ & $\mathbf{8 5 , 7}$ \\
\hline
\end{tabular}

Fonte: Projeto "Mapeamento do sistema partidário pelotense (1982.2004)" - Grupo de Pesquisa "Sistema político - eleições, partidos e relações Executivo-Legislativo" (Instituto de Sociologia e Política da Universidade Federal de Pelotas).

A principal diferença entre as duas tabelas confirma o que foi especulado anteriormente: quando é admitida a possibilidade de substituição dos parlamentares eleitos, o número de desistências diminui, assim como aumenta o de recandidaturas. Enquanto 81,7\% (103 em 126) dos vereadores eleitos entre 1976 e 2000 procuraram concorrer a um novo mandato nas eleições imediatamente subseqüentes; no mesmo período, o índice que contempla mudanças na nominata dos eleitos foi de 85,7\% (108 em 126). As desistências ficaram na ordem de $18,3 \%$, quando são considerados apenas os vereadores eleitos (23 em 126) e de $14,3 \%$, quando as trocas de titularidade aceitas (18 em 126).

Independentemente dessas diferenças, é possível constatar que a regra geral é a de que a grande maioria dos vereadores de Pelotas se reapresente (índices sempre acima de $80 \%$ ). Esses valores são significativamente mais altos do que aqueles calculados no mesmo período para a Câmara dos Deputados, os quais raramente chegam a $70 \%$, ainda que se pondere que, por não considerarem as substituições, eles tendam a registrar um índice menor de recandidaturas (FIGUEIREDO e LIMONGI, 1996; ARAÚJO, 2002; SANTOS, 2002; LEONI, PEREIRA e RENNÓ, 2003). 
Na interpretação de Figueiredo e Limongi (1996, p.20), a "proporção de candidaturas à reeleição pode ser tomada como um indicador do valor do mandato parlamentar", com o que concorda Schmitt (1999, p.137). Concebemos, porém, que os índices superiores de recandidaturas entre os vereadores, na comparação com os deputados federais, mais do que indicarem maior valorização do mandato, refletem o menor elenco de opções deles para a continuidade da carreira e, conseqüentemente, a maior dificuldade relativa para que alcancem a ascensão.

Por ser um status superior em relação aos vereadores, ser deputado federal implica possibilidades mais amplas e variada s de ocupação de espaços políticos: continuar como deputado, tornar-se prefeito ou governador, receber nomeação para ministérios, empresas estatais ou órgãos administrativos da esfera federal, bem como secretarias de governo estadual ${ }^{12}$.

As perspectivas de um vereador são mais limitadas, pois raramente ele é nomeado para algum cargo de alto valor estratégico na escala federal e praticamente não tem opções de postos políticos eletivos de menor expressão. Logo, o que ele pode pretender é permanecer no cargo e, em caso de se tratar de progressão na carreira, tornar-se prefeito, deputado federal ou estadual; ser nomeado para alguma secretaria ou órgão administrativo estadual, e secretaria municipal. Soma-se a isso que,

"a decisão estratégica ou escolha que os legisladores fazem com relação a qual cargo vão concorrer na próxima eleição é orientada principalmente por uma auto-avaliação do desempenho no cargo e das chances de ter êxito nas eleições. Em outras palavras, as escolhas de carreira do legislador não são orientadas apenas pelas compensações do cargo pretendido, tais como remuneração mais alta ou equipe maior, mas também pela viabilidade eleitoral dessa escolha. Isto é, a utilidade maior de ser eleito para esses cargos deve ser ponderada pela sua menor probabilidade de sucesso e levar em conta os diferentes custos embutidos em cada escolha" (LEONI, PEREIRA e RENNÓ, 2003, p.46).

Nessa escala de possibilidades e de riscos, permanecer como vereador torna-se uma decisão bastante razoável, apesar de ser uma "ambição estática"13, e que ganha reforço quando é acrescentada a grandeza eleitoral do município ou da

\footnotetext{
${ }^{12} \mathrm{O}$ horizonte para a continuidade da carreira é tão amplo para os deputados federais que, além da ambição estática (concorrer à reeleição) e progressiva (disputar cargos mais altos), Leoni, Pereira e Rennó encontraram mesmo casos de ambição regressiva (concorrer a deputado estadual).

${ }^{13}$ Não foi realizado estudo sistemático, mas a carreira de vereador parece ser mais longa e estável do que a de deputado, muito em função da diferença na escala de possibilidades e de custos que envolvem cada uma. Em Pelotas, há exemplos de vereadores da legislatura 2005-08 que estão no cargo há nove (Macluf), seis (Adalim Medeiros) e cinco mandatos consecutivos (Milton Martins, Otávio Soares).
} 
região em relação a outras partes do distrito ${ }^{14}$. Isso não significa que os vereadores não busquem cargos de deputado: a partir de 1986, quando as disputas deixaram de ser coincidentes, e estimulados pelos partidos que procuram candidaturas regionais para reforçar a listagem, uma parcela significativa tem concorrido a deputado.

A questão é que eles não obtêm êxito, o que os coloca, dois anos depois, novamente frente à questão da continuidade da carreira. $O$ destino daqueles que decidiram não disputar a reeleição, a ser detalhado a seguir, consolida esta inferência: em sua maioria, eles querem um cargo superior (no caso deste estudo, prefeito, vice ou deputado estadual), sendo que a quase totalidade não obteve sucesso ${ }^{15}$.

As desistências chegam a dezoito em seis pleitos, média de três por legislatura. A incidência foi mais alta em 1992 e em 1996 (quatro ou 19\%) e ficou na média em 1982 e em 1988. Nas duas eleições mais recentes foi registrado o menor número de desistências (duas), sendo que em 2004, em razão da redução no número de cadeiras, a disputa pela reeleição se apresentou como a mais difícil.

Grohmann (apud ARAÚJO, 2002, p.21-22) lista quatro causas para as desistências: saída voluntária (para não concorrer, para concorrer em outro nível eleitoral ou para assumir um cargo político-administrativo) ${ }^{16}$; impedimento por lei; morte ou doença; estratégia ou decisão partidária de não aprovar as candidaturas.

Dessas, a última jamais foi registrada na Câmara de Vereadores de Pelotas. Houve um único episódio de morte, mas ele não figura como "desistência" e sim com substituição do vereador. Dos dezoito casos, uma ocorrência seria identificada como "impedimento legal" e dezesete como "saída voluntária", conforme a classificação proposta por Grohman. Preferimos, no entanto, desdobrar as categorias, como se verifica a seguir:

\footnotetext{
${ }^{14} \mathrm{Em}$ municípios ou regiões com densidade eleitoral maior, como as capitais ou as regiões metropolitanas, em tese, os vereadores têm maiores estímulos para buscarem cargos de maior prestígio - especulação que necessita de comprovação empírica.

${ }^{15} \mathrm{O}$ alto índice de fracasso dos vereadores que apresentam ambição progressiva refere-se somente àqueles que concluíram o mandato. $O$ quadro não muda significativamente se forem acrescentados os titulares que renunciaram exatamente porque obtiveram êxito na busca de ascensão na carreira: como foi visto anteriormente, houve apenas três casos de vereadores de Pelotas que se tornaram deputados. ${ }^{16}$ Podem ser acrescentadas outras possibilidades de "saída voluntária", como aposentadoria e abandono da carreira.
} 
Tabela 3. Motivo pelo qual os vereadores não se reapresentaram para um novo mandato, em Pelotas, nas eleições (1982-2004)

\begin{tabular}{|l|c|c|}
\cline { 2 - 3 } \multicolumn{1}{c|}{} & Freqüência & $\mathbf{\%}$ \\
\hline Concorreu a outro cargo & $\mathbf{1 1}$ & $\mathbf{6 1 , 1}$ \\
\hline Prefeito ou Vice & 9 & 50,0 \\
\hline Deputado & 2 & 11,1 \\
\hline Decidiu não concorrer & $\mathbf{6}$ & $\mathbf{3 3 , 3}$ \\
\hline Aposentadoria & 2 & 11,1 \\
\hline Abandono da carreira & 2 & 11,1 \\
\hline Interrupção na carreira & 2 & 11,1 \\
\hline Tornou-se inelegível & $\mathbf{1}$ & $\mathbf{5 , 6}$ \\
\hline Total & $\mathbf{1 8}$ & $\mathbf{1 0 0}$ \\
\hline
\end{tabular}

Fonte: Projeto "Mapeamento do sistema partidário pelotense (1982-2004)"

- Grupo de Pesquisa "Sistema político - eleições, partidos e relações Executivo-Legislativo" (Instituto de Sociologia e Política da Universidade Federal de Pelotas).

A maior causa das desistências é a decisão de concorrer a outro cargo eletivo $(61,1 \%)$, sendo que a preferência recai por um cargo majoritário $(50 \%$ de todas as não reapresentações), seja para Prefeito, seja para Vice. Em uma dessas ocasiões, um político (Elberto Madruga) acabou por concorrer a Chefe do Executivo em outro município, Capão do Leão, que havia se emancipado de Pelotas em 1982. Aliás, ele foi o único que conseguiu ser bem sucedido.

Dessa maneira, no município, a pretensão de ocupar um cargo eletivo na Prefeitura tem sido o grande estímulo para que um vereador não concorra à reeleição, sendo que esta escolha se mostrou, no período analisado, como de alto risco. Apenas em 2000 não ocorreu nenhuma desistência para disputar o Executivo.

Em dois casos, os vereadores buscaram o cargo de deputado estadual. Isto ocorreu em 1982, face às peculiaridades daquele pleito, quando as disputas para os legislativos federal, estadual e municipal foram concomitantes. Essa situação não mais se repetiu, pois, desde então, as disputas municipais e estaduais ou nacionais ocorrem em anos distintos. Em outras palavras: ao buscarem uma vaga na Assembléia Legislativa, foram forçados a desistirem da tentativa de um novo mandato de vereador, no entanto, nenhum dos dois conseguiu se reeleger.

Há seis casos (um terço das desistências) de políticos que "decidiram não concorrer", os quais contemplam três situações diferenciadas. Dois resolveram "aposentar-se", após uma carreira política longa ${ }^{17}$. Outros dois, em primeiro mandato, anunciaram que abandonavam a carreira em razão da decepção com a

\footnotetext{
${ }^{17}$ Raimundo Vieira da Cunha, em 1988, e Mário Fonseca da Silveira, em 1992.
} 
atividade política ${ }^{18}$. Finalmente, os dois restantes "deram um tempo", ou seja, interromperam circunstancialmente a atividade ${ }^{19}$.

O vereador Flávio Coswig tornou-se inelegível. Na legislatura 1997-2000, ele mudou o domicílio eleitoral para Arroio do Padre, com vistas a concorrer a prefeito nesse novo município, emancipado de Pelotas. O pleito (que deveria ocorrer em 2000) foi cancelado pela Justiça Eleitoral e todos os alistados naquela localidade ficaram impedidos de disputar eleições, inclusive no município de origem.

Tabela 4. Renovação compulsória na Câmara de Vereadores de Pelotas calculada a partir dos parlamentares que iniciaram a legislatura (1982-2004)

\begin{tabular}{|c|c|c|c|}
\cline { 2 - 4 } \multicolumn{1}{c|}{} & $\begin{array}{l}\text { Vereadores } \\
\text { /Vagas }\end{array}$ & Desistências & $\begin{array}{l}\text { Renovação } \\
\text { Compulsória }\end{array}$ \\
\hline $\mathbf{1 9 8 2}$ & 21 & 4 & 19,0 \\
\hline $\mathbf{1 9 8 8}$ & 21 & 5 & 23,8 \\
\hline $\mathbf{1 9 9 2}$ & 21 & 4 & 19,0 \\
\hline $\mathbf{1 9 9 6}$ & 21 & 4 & 19,0 \\
\hline $\mathbf{2 0 0 0}$ & 21 & 4 & 19,0 \\
\hline Total & $\mathbf{1 0 5}$ & $\mathbf{2 1}$ & $\mathbf{2 0 , 0}$ \\
\hline
\end{tabular}

Fonte: Projeto "Mapeamento do sistema partidário pelotense (1982-2004)" Grupo de Pesquisa "Sistema político - eleições, partidos e relações Executivo. Legislativo" (Instituto de Sociologia e Política da Universidade Federal de Pelotas).

\footnotetext{
${ }^{18}$ Virgínia Fetter Gomes, em 1996, e Deogar Soares, em 2000.

${ }^{19}$ Mário Filho e Ricardo Nogueira, ambos em 1992, sendo que Mário Filho foi eleito, em 2000, viceprefeito de Pelotas.
} 


\section{Tabela 5. Renovação compulsória, na Câmara de Vereadores de Pelotas considerando os parlamentares que encerraram o mandato}

\begin{tabular}{|c|c|c|c|}
\hline & $\begin{array}{l}\text { Vereadores } \\
\text { /Vagas }\end{array}$ & Desistências & $\begin{array}{l}\text { Renovação } \\
\text { Compulsória }\end{array}$ \\
\hline 1982 & 21 & 3 & 14,3 \\
\hline 1988 & 21 & 3 & 14,3 \\
\hline 1992 & 21 & 4 & 19,0 \\
\hline 1996 & 21 & 4 & 19,0 \\
\hline 2000 & 21 & 2 & 9,5 \\
\hline Total & 105 & 16 & 15,2 \\
\hline
\end{tabular}

Alguns esclarecimentos a respeito das Tabelas 4 e 5 . Nelas, ao contrário das três primeiras, a totalização é realizada para o período $1982 \cdot 2000$, sem considerar o pleito de 2004. A razão é que, na disputa mais recente, houve a diminuição no número de cadeiras, logo, a "renovação compulsória" só estaria garantida se o total de desistências fosse maior do que a redução no número de vagas, o que não ocorreu: a Câmara encolheu em seis vagas, apenas dois vereadores desistiram e 19 pleitearam uma das 15 cadeiras. Desse modo, seria possível que todas os assentos da legislatura 2005-2008 fossem ocupados por vereadores que estavam no período anterior ${ }^{20}$.

Outra conseqüência da redução é que deixou de existir a associação entre "renovação compulsória" e "desistência" (que pode ser observada nas Tabelas 1 e 4, 2 e 5). A "desistência" pode ser calculada para a totalidade do período, pois corresponde ao número de vereadores que deixaram de concorrer, dentre aqueles que detinham o mandato, mas deixa de equivaler, em 2004, à "renovação compulsória", que é calculada sobre o número de vagas em disputa. Em outras palavras, uma refere-se a quem já possui mandato e a outra aos que terão mandato por causa de não recandidaturas. Este também é o motivo porque se apresentaram essas informações em tabelas distintas.

As diferenças entre as incidências de "renovação compulsória", apresentadas pelas Tabelas 4 e 5, explicam-se do mesmo modo que aquelas

\footnotetext{
${ }^{20}$ Sendo assim, a projeção de "renovação compulsória" para o período 1982-2004 deveria ser de 13,3\% (16 em 120 vagas disponíveis).
} 
BARRETO, A. Reeleição parlamentar: reflexões metodológicas e análise...

apontadas em relação às anteriores: a inclusão de suplentes que substituem definitivamente parlamentares que falecem ou renunciam ao mandato faz com que o índice da "renovação" seja menor, tenmdo em vista que a tendência é de que estes se reapresentem (o que ocorreu nas cinco substituições incorporadas pela pesquisa).

Quanto aos resultados, entre os pleitos de 1982 e de 2000, a perspectiva média de mudança na composição da Câmara de Vereadores, sem o teste das urnas e independentemente da vontade do eleitor, ficou na ordem de $15 \%$ a $20 \%$.

\section{2 - Reeleição}

A seguir, na Tabela 6 , estão analisados os dados relativos aos vereadores que terminaram a legislatura e buscaram um novo mandato:

Tabela 6. Vereadores concorrentes e resultado obtido (1982-2004)

\begin{tabular}{|c|c|c|c|c|c|c|}
\cline { 2 - 7 } \multicolumn{1}{c|}{} & Concorrentes & Reeleitos & $\begin{array}{c}\text { Não } \\
\text { reeleitos }\end{array}$ & Vagas & $\begin{array}{c}\text { Taxa } \\
\text { Reeleição }\end{array}$ & $\begin{array}{c}\text { Renovação } \\
\text { Líquida }\end{array}$ \\
\hline $\mathbf{1 9 8 2}$ & 18 & 11 & 7 & 21 & 61,1 & 38,9 \\
\hline $\mathbf{1 9 8 8}$ & 18 & 10 & 8 & 21 & 55,6 & 44,4 \\
\hline $\mathbf{1 9 9 2}$ & 17 & 8 & 9 & 21 & 47,1 & 52,9 \\
\hline $\mathbf{1 9 9 6}$ & 17 & 15 & 2 & 21 & 88,2 & 11,8 \\
\hline $\mathbf{2 0 0 0}$ & 19 & 14 & 5 & 21 & 73,7 & 26,3 \\
\hline Subtotal & $\mathbf{8 9}$ & $\mathbf{5 8}$ & $\mathbf{3 1}$ & $\mathbf{1 0 5}$ & $\mathbf{6 5 , 2}$ & $\mathbf{3 4 , 8}$ \\
\hline $\mathbf{2 0 0 4}$ & 19 & 9 & 10 & 15 & 47,4 & 52,6 \\
\hline Total & $\mathbf{1 0 8}$ & $\mathbf{6 7}$ & $\mathbf{4 1}$ & $\mathbf{1 2 0}$ & $\mathbf{6 2 , 0}$ & $\mathbf{3 8 , 0}$ \\
\hline
\end{tabular}

Fonte: Projeto "Mapeamento do sistema partidário pelotense (1982-2004)" - Grupo de Pesquisa "Sistema político - eleições, partidos e relações Executivo-Legislativo" (Instituto de Sociologia e Política da Universidade Federal de Pelotas).

Em números absolutos, têm-se 67 sucessos em 108 reapresentações. Sob qualquer modo de considerar os dados, a "taxa de reeleição" fica sempre acima de $60 \%$ : é de $62 \%$ no período, e de $65,2 \%$ (58 em 89 reapresentações) se o pleito de 2004 for retirado, pelas razões já apresentadas. Contudo, é preciso lembrar que nesta eleição havia 15 vagas disponíveis e 19 recandidaturas, logo a "taxa de reeleição" poderia atingir, no máximo, 78,9\%, o que permite ponderar que os 47,4\% calculados (nove reeleições em 19 reapresentações) equivalem a 60\% da 
taxa máxima possível daquele pleito ${ }^{21}$. Pode-se, ainda, calcular o sucesso sobre o total de vagas disponíveis (nove em 15), o que também resulta em uma "taxa de reeleição" de 60\%. Se for considerado este índice para 2004 e ele for agregado aos demais, a taxa média de reeleição será de 64,3\% entre 1982 e 2004.

Noutra face da moeda, o número absoluto de fracassos ou insucessos é de 41 em 108 tentativas. A "taxa de renovação líquida" fica na ordem de 38\% no período, e cai para 34,8\% entre 1982 e 2000 (31 em 89 concorrentes). A taxa ponderada do pleito de 2004 estabelece-se em 40\% e, se for incorporada à análise, a média do período 1982-2004 passa a ser de 35,7\% 22 .

Independentemente dos resultados apresentados pelas diferentes possibilidades de calcular os índices, fica evidente que a maioria dos vereadores que se apresenta para um novo mandato consegue a reeleição (de 62 a 64\%). Em contrapartida, a mudança realizada pelas urnas fica na ordem de 36 a $38 \%$.

A "taxa de reeleição" apresentada pela Câmara de Vereadores de Pelotas é um pouco superior aquela calculada para a Câmara dos Deputados para o mesmo período, que fica entre 57\% a 60\% (FIGUEIREDO e LIMONGI, 1996; SANTOS, 1997, 2002).

Os significados políticos desses índices não são consensuais na bibliografia: os autores costumam se dividir entre aqueles que apontam o aspecto positivo da renovação e os negativos da manutenção, e vice-versa. Santos evidencia não conhecer "hipótese sobre o composto ótimo entre renovação e conservação (...)" (SANTOS, 1997, p.33-38). Destaca ainda que:

“(...) para efeito de socialização política dos representantes a existência de um quantum de socialização política, de permanência de representações anteriores, é indispensável. Toda uma tradição de análise política, de outro lado, acentua a necessidade de renovação da elite política como suprema estratégia no sentido de evitar a decadência do sistema político. Mosca e Pareto, sobretudo, mas também Michels, em certo sentido, assinalam os riscos de um fechamento do grupo dirigente, conduzindo a uma incapacidade de inovar comportamentos e respostas face a novas e velhas situações. O requisito de renovação decorre assim da mesma fonte de onde decorre o requisito de permanência, a saber, a eficácia política da representação" (SANTOS, 1971, p.19).

\footnotetext{
${ }^{21}$ Uma fórmula mais simples acrescenta o total de vagas retiradas da Câmara tanto ao número de reapresentações, quanto ao de reeleições, antes de multiplicar o produto da divisão por 100.

22É preciso ressalvar que a variação no número de cadeiras disponíveis não é tão determinante para a ocorrência dos fracassos quanto o é para os sucessos.
} 
Novaes (1993) Contrapõe que a maioria de parlamentares novatos afeta a dinâmica do processo legislativo, ao facilitar o trabalho daqueles que controlam de fato as peculiaridades de funcionamento deste processo. Figueiredo e Limongi (1996), por sua vez, não avaliam a questão pela ótica da instituição, e sim dos próprios parlamentares. Eles afirmam que as altas taxas de renovação parlamentar podem ser explicadas pela falta de atrativos da carreira, como o acesso limitado a recursos políticos capazes de proporcionar dividendos eleitorais significativos, o que leva os políticos a buscarem postos mais atrativos.

O argumento de Samuels (2000) é distinto, mas não contrário: a alta rotatividade reflete a lógica de funcionamento do sistema eleitoral e a escala de perspectivas da carreira política. Os parlamentares mais qualificados são também aqueles que têm maior expectativa de sucesso eleitoral, razão pela qual concorrem a cargos mais importantes. Aqueles que disputam a reeleição são os menos qualificados, os que têm menos possibilidades de ascensão, assim como os que correm mais riscos de fracassarem, por isso, a não reeleição é alta e, conseqüentemente, novos políticos chegam ao parlamento.

Figueiredo e Limongi (1996), por fim, afirmam que as tentativas bemsucedidas de manutenção no cargo são um indicador da institucionalização do sistema partidário, visto que o eleitor prefere manter um representante já conhecido a eleger um novato e a reeleição serve como prêmio ao parlamentar que optou por investir na carreira.

Seguindo este caminho, pode-se dizer que, se a grande maioria dos vereadores (mais de $80 \%$ ) procura investir na continuidade da carreira e seja por efetiva valorização do cargo, ou seja por falta de alternativas mais viáveis para manter-se em cargos públicos, a parcela majoritária tem sido recompensada (62 a 64\%). Esse fato também mostra o acerto daqueles que buscam a reeleição e a importância da condição de vereador para a manutenção do cargo. No entanto, como será abordado mais adiante, este não é um investimento alheio a riscos; ao contrário, o índice de insucesso não pode ser considerado desprezível (36 a 38\%).

Devemos ponderar também que a "taxa de reeleição" não é uniforme, ela tem variado de modo significativo, conforme o pleito: em 1992 foi a menor do período (47,1\%), inferior, inclusive, a que foi registrada em 2004 (47,4\%), quando a probabilidade de sucesso era menor por causa da redução no número de cadeiras (e chega a $60 \%$, quando ponderada). Estas, aliás, são as duas eleições em que, ao contrário da média geral, o índice de derrotas ou de "renovação líquida" superou os 50\%. O mais alto índice de reeleição foi registrado em 1996 (88,2\%): houve apenas dois insucessos em 17 recandidaturas. O pleito de 2000, com 73,7\% (14 reeleitos em 19 reapresentações), também ficou acima da média. 
A partir dessas informações, é possível considerar que, nos dois primeiros pleitos analisados (1982 e 1988), a "taxa de reeleição" ficou na ordem de 60\%, próxima à média do período. Em 1992 ocorreu uma sensível queda e, conseqüentemente, um índice elevado de não reeleição (mais da metade dos postulantes). Passado esse fenômeno que implicou "renovação líquida" significativa na Câmara (52,9\%), em 1996 e em 2000 houve baixo índice de "renovação líquida": no mínimo $73 \%$ dos vereadores que concorreram garantiram mais um mandato. Esta tendência foi interrompida em 2004, em função da redução no número de cadeiras, o que trouxe o índice de reeleição ao patamar apresentado em 1992. Porém, se for utilizado o cálculo ponderado, o índice continua menor em comparação a 1996 e a 2000, mas fica no nível apresentado em 1982 e em 1988, ou seja, não repete o valor atingido em 1992. Este se afirma, assim, como o pior do período e a exceção em comparação aos demais.

A Tabela 7 reúne as informações relativas aos vereadores que desistiram e aos que, tendo se reapresentado, obtiveram ou não a reeleição. Desse modo, é possível calcular a "taxa de permanência", o percentual de vereadores que continuariam de uma legislatura para outra, bem como o contrário dela, a "renovação bruta", o índice que mede o percentual dos que, necessariamente, seriam diferentes em relação à legislatura anterior, constantes na Tabela 8.

Tabela 7. Situação apresentada na eleição seguinte pelos vereadores de Pelotas que concluíram o mandato, e número de novos na próxima legislatura (1982-2004)

\begin{tabular}{|c|c|c|c|c|c|c|}
\cline { 2 - 7 } \multicolumn{1}{c|}{} & Vereadores & Desistentes & $\begin{array}{c}\text { Não } \\
\text { reeleitos }\end{array}$ & Reeleitos & Novos & Vagas \\
\hline $\mathbf{1 9 8 2}$ & 21 & 3 & 7 & 11 & 10 & 21 \\
\hline $\mathbf{1 9 8 8}$ & 21 & 3 & 8 & 10 & 11 & 21 \\
\hline $\mathbf{1 9 9 2}$ & 21 & 4 & 9 & 8 & 13 & 21 \\
\hline $\mathbf{1 9 9 6}$ & 21 & 4 & 2 & 15 & 6 & 21 \\
\hline $\mathbf{2 0 0 0}$ & 21 & 2 & 5 & 14 & 7 & 21 \\
\hline $\mathbf{2 0 0 4}$ & 21 & 2 & 10 & 9 & 6 & 15 \\
\hline Total & $\mathbf{1 2 6}$ & $\mathbf{1 8}$ & $\mathbf{4 1}$ & $\mathbf{6 7}$ & $\mathbf{5 3}$ & $\mathbf{1 2 0}$ \\
\hline
\end{tabular}

Fonte: Projeto "Mapeamento do sistema partidário pelotense (1982-2004)" · Grupo de Pesquisa "Sistema político - eleições, partidos e relações Executivo-Legislativo" (Instituto de Sociologia e Política da Universidade Federal de Pelotas). 


\section{Tabela 8. Taxa de permanência e de renovação bruta nas eleições para a Câmara de Vereadores de Pelotas (1982-2004)}

\begin{tabular}{|c|c|c|}
\cline { 2 - 3 } \multicolumn{1}{c|}{} & Taxa Permanência & Renovação Bruta \\
\hline 1982 & 52,4 & 47,1 \\
\hline 1988 & 47,6 & 52,4 \\
\hline 1992 & 38,1 & 61,9 \\
\hline 1996 & 71,4 & 28,6 \\
\hline 2000 & 66,7 & 33,3 \\
\hline Subtotal & $\mathbf{5 5 , 2}$ & $\mathbf{4 4 , 8}$ \\
\hline 2004 & 60,0 & $\mathbf{4 0 , 0}$ \\
\hline Total & $\mathbf{5 5 , 8}$ & $\mathbf{4 4 , 2}$ \\
\hline
\end{tabular}

Fonte: Projeto "Mapeamento do sistema partidário pelotense (1982-2004)" Grupo de Pesquisa "Sistema político - eleições, partidos e relações ExecutivoLegislativo" (Instituto de Sociologia e Política da Universidade Federal de Pelotas).

De 126 vereadores analisados, 18 desistiram e 108 se reapresentaram. Desses, 67 foram reeleitos e 41 derrotados. Isso significa que 59 parlamentares deixaram a Câmara no período. Por outro lado, como no pleito de 2004 havia 15 vagas disponíveis, e não 21 , o total de cadeiras oferecidas nas eleições no período 1982-2004 foi de 120, as quais foram conquistadas por 53 novos parlamentares.

A "taxa de permanência" no período de 1982 a 2004 foi de 55,8\%, logo, um pouco mais da metade dos vereadores se manteve na Câmara de uma legislatura para outra. A "renovação bruta", em contrapartida, ficou em 44,2\%.

O índice de permanência mais alto foi registrado em $1996(71,4 \%)$ e o mais baixo em 1992 (38,1\%). Ao longo do tempo, persistem as tendências apresentadas anteriormente: comportamento uniforme em 1982 e em 1988, com percentuais próximos à média acumulada $(52,4 \%$ e 47,6\%, respectivamente); queda significativa em 1992 (38,1\%); recorde em 1996 (71,4\%); finalmente, permanência significativamente acima da média em 2000 (66,7\%).

Deve-se destacar que o cálculo para o pleito de 2004 mostra-se mais nuançado. Nove dos 21 vereadores que concluíram a legislatura 2001-2004 permaneceram na Câmara em 2005-2008, o que equivale a uma "taxa de retorno" de 42,9\%. Entretanto, como na legislatura 2005-2008 haveria 15 vagas, nove (ou $60 \%$ ) seriam ocupadas por vereadores vindos do período anterior. O mesmo vale para a "renovação bruta": 12 dos 21 vereadores que concluíram o mandato em 
2004 não estariam na Câmara a partir de 2005 (57,1\%). Porém, em vista da perda de seis cadeiras, não seriam nove os vereadores novos, e sim seis (40\%).

Uma pequena referência à distinção de Fleischer (1980, p.58) entre parlamentares "calouros" e "novatos". Dentre os 53 vereadores novos, há apenas três "novatos" (cerca de 10\%), ou seja, políticos que já haviam ocupado o cargo em legislaturas anteriores, tiveram a carreira interrompida e retornaram à Câmara ${ }^{23}$. Os 50 candidatos restantes nunca haviam sido vereadores. Se for adotado um conceito rigoroso de "renovação", o qual compreenda apenas parlamentares "calouros", o índice do período passa de 44,2\% (53 em 120) para 41,7\% (50 em 120).

Outro detalhe revelado por esta informação é que a quase totalidade dos que deixaram a Câmara, seja por desistência, seja por derrota, não obtiveram um novo mandato (56 em 59, cerca de 95\%). Como a maior parte dos casos de saída é por derrota (41 em 59, quase 70\%), torna-se evidente que não conseguir renovar o mandato nas urnas significa o término da carreira de vereador. No período analisado, em 41 situações houve apenas um caso de parlamentar não reeleito que conseguiu tornar-se vereador em pleito posterior $(2,4 \%)^{24}$.

Portanto, a permanência na carreira é sempre preocupante para um vereador. Como visto, no período analisado, a maior parte deles (cerca de 80\%) acaba por ter de buscar a reeleição, por falta de opções ou com vistas a minimizar riscos, o que torna a concorrência bastante intensa. Embora a maioria atinja a reeleição (pouco mais de $60 \%$ ), verificamos que fracassar nas urnas - situação que atinge aproximadamente $35 \%$-, além de ser um risco sempre presente, assume significado muito drástico, visto que é, em praticamente $95 \%$ dos casos, resultado irreversível. E se é fato que a grande maioria tem esta como a alternativa viável para manter-se na carreira, perder o cargo significa, muito provavelmente, o término da carreira como detentor de mandato público eletivo ${ }^{25}$.

\footnotetext{
${ }^{23}$ Flávio Coswig (vereador de 1976 a 1988, que retornou em 1996), Cecília Hypólito (vereadora de 1988 a 1992, eleita em 1996) e Jones Maschio (parlamentar de 1988 a 1992, tendo retornado em 2000). Coswig e Hypólito deixaram o cargo por desistência (ambos concorreram a prefeito de Pelotas pela coligação liderada pelo PT), e Maschio foi derrotado nas urnas em 1992.

${ }^{24}$ Trata-se de Jones Maschio, citado na nota anterior.

${ }^{25}$ Isso não implica dizer o final da carreira como "homem público", pois grande parte passa a ocupar cargos por nomeação. Nesse sentido, o que eles perdem é o protagonismo oferecido pelo fato de deter um cargo eletivo.
} 
BARRETO, A. Reeleição parlamentar: reflexões metodológicas e análise...

\section{Conclusão}

Este artigo procurou recuperar as categorias desenvolvidas pelos trabalhos dedicados ao tema, tais como "renovação" (em suas variadas acepções), "reapresentação", "desistência", "reeleição". Enfatizou as aproximações e as diferenças de concepções apresentadas pelos autores, bem como as fórmulas que visam operacionalizar essas variáveis, uma vez que os estudos estão voltados ao estabelecimento de parâmetros quantitativos para apreciação dos fenômenos.

Em um segundo momento, buscou discutir alguns dos aspectos metodológicos ligados a tais operacionalizações que pareceram falhos, limitados ou excessivamente condicionantes aos resultados a serem apurados. $\mathrm{O}$ foco primordial da crítica liga-se à tentativa de formular um estudo que, apesar de essencialmente quantitativo, estivesse metodologicamente apto a perceber a diversidade de conjunturas mais do que simplesmente buscar inserir a dinamicidade dos fatos políticos em padrões previamente definidos.

Esse é o caso da decisão seguida por muitos pesquisadores de calcular a "renovação" a partir da listagem dos parlamentares que foram eleitos na disputa anterior, sem admitir substituições ao longo do mandato, o que implica a tendência de obter índices mais altos. Argumentamos que, em muitas ocasiões, os titulares morrem ou renunciam ao mandato e são substituídos por suplentes, os quais são reconhecidos como parlamentares e, nessa condição, candidatos à reeleição, sendo que muitos obtêm sucesso. Logo, a "renovação" registrada pelo modelo que não reconhece substituições não corresponde à realidade política, seja da legislatura, seja da disputa e do resultado eleitoral.

Discutimos ainda o fato de que as categorias operacionais não incluem a possibilidade de redução no número de cadeiras, situação que ocorreu no caso das Câmaras de Vereadores de Pelotas em 2004, e que afeta os índices a serem calculados. Ao estudar-se essa situação, observamos que deixa de ocorrer a vinculação entre "renovação compulsória" e "desistência" e foi revelado que, embora associados, os conceitos não são equivalentes, pois um refere-se a quem já possui mandato e o outro aos que terão mandato por causa de não recandidaturas.

Finalmente, apresentamos os dados relativos à Câmara de Vereadores de Pelotas, entre 1976 e 2004. De 126 vereadores analisados, 18 desistiram e 108 se reapresentaram. Desses, 67 foram reeleitos e 41 derrotados. Isso significa que 59 parlamentares deixaram a Câmara no período. Por outro lado, como no pleito de 2004 havia 15 vagas disponíveis, e não 21, o total de cadeiras oferecidas nas eleições no período $1982-2004$ foi de 120 , as quais foram conquistadas por 53 novos parlamentares. 
Foi constatado que mais de $80 \%$ dos vereadores de Pelotas se reapresentaram, índice significativamente mais alto do que aqueles calculados no mesmo período para a Câmara dos Deputados. As razões para tal refletem o menor elenco de opções dos vereadores para a continuidade da carreira e, conseqüentemente, a maior dificuldade relativa para que alcancem a ascensão. Diante desse quadro, permanecer como vereador torna-se uma decisão bastante razoável para manter-se na carreira.

A maior causa de desistência é a decisão de concorrer a outro cargo eletivo $(61,1 \%)$, sendo que a preferência recai por um cargo majoritário (50\% de todas as não reapresentações). Evidenciou-se ser esta uma opção de alto risco, pois nenhum dos vereadores conseguiu ser bem sucedido.

A parcela majoritária (62\% a 64\%) dos vereadores procura investir na continuidade da carreira, mas esta também não é uma operação alheia a riscos: o índice de insucesso de $36 \%$ a $38 \%$ não pode ser considerado desprezível, ainda mais porque há apenas um caso de derrotado nas urnas que conseguiu eleger-se posteriormente. Em outros termos: não se reeleger implica o final da carreira de vereador, o que se torna mais grave ao ponderar-se que, para a grande maioria, permanecer no cargo é a única opção viável de manutenção da carreira como detentor de cargo eletivo.

\section{Referências bibliográficas}

ARAÚJO, A. F. O retorno ao pluripartidarismo: a reorganização partidária em Pelotas (1979-1982). Monografia em Ciências Sociais. Pelotas: Universidade Federal de Pelotas,2006.

ARAúJO, S. C. A Renovação parlamentar no Brasil. Dissertação de Mestrado em Ciência Política. Rio de Janeiro: IUPERJ, 2002.

BARRETO, A. Mapeamento da distribuição de cadeiras de vereador em Pelotas (RS), entre os partidos políticos, conforme as eleições do período 1982-2004. Pelotas : UFPel, 2007a.

- Impacto da coligação nas eleições proporcionais: o caso da Câmara de

Vereadores de Pelotas (1988-2004). Pelotas: UFPel, 2007b. 
BOTERO, F. e RENNÓ, L. "Career choice and legislative reelection - evidence from Brazil and Colombia". Brazilian Political Science Review. Rio de Janeiro: ABCP (1), mar.2007.

CARNEIRO, L. P.; SCHMITT, R. A. "Eleições casadas, resultados nem sempre solteiros: campanhas proporcionais e imagem partidária no Horário Gratuito de Propaganda Eleitoral". Opinião Publica, vol. 3, $\mathrm{n}^{\circ} 1,2001$.

ECHEVERRY, J. V. O poder legislativo pelotense. Pelotas: Cadernos de Pelotas 2,1990.

FIGUEIREDO, A. e LIMONGI, F. "Congresso Nacional: organização, processo legislativo e produção legal. Cadernos de Pesquisa Cebrap. São Paulo: Entrelinhas 5, out.1996

FLEISCHER, D. “Renovação política - Brasil 1978: eleições parlamentares sob a égide do 'Pacote de Abril'”. Revista de Ciência Política. Rio de Janeiro: Fundação Getúlio Vargas, vol.23, $n^{\circ} 2,1980$.

. "O Pluripartidarismo no Brasil: dimensões socioeconômicas e regionais do recrutamento legislativo (1946-1967)". Revista de Ciência Política. Rio de Janeiro: Fundação Getúlio Vargas, vol.24, n¹, 1981.

LEONI, E. e PEREIRA, C. e RENNÓ, L.. "Estratégias para sobreviver politicamente: escolhas de carreiras na Câmara de Deputados do Brasil”. Opinião Publica, vol.9, n¹, maio 2003.

MAINWARING, S. Sistemas partidários em novas democracias: o caso do Brasil. Rio de Janeiro/Porto Alegre: Fundação Getúlio Vargas/Mercado Livre, 2001.

"Políticos, partidos e sistemas eleitorais: o Brasil numa perspectiva comparativa". Novos Estudos Cebrap, vol.29, 1991.

NOVAES, C. A. M. "Dinâmica institucional da representação: individualismo e partidos na Câmara dos Deputados". Novos Estudos Cebrap, vol.38, 1994.

PEREIRA, C.; RENNÓ, L. "O que é que o reeleito tem? Dinâmicas político-institucionais locais e nacionais nas eleições de 1998 para a Câmara dos Deputados". Dados, vol.44, n², 2001.

SAMUELS, D. "Ambition and competition: explaining legislative turnover in Brazil". Legislative Studies Quarterly, vol.25, 2000.

SANTOS, F. "Recruitment and Retention of Legislators in Brazil". Legislative Studies Quarterly, vol. 24, 1999.

SANTOS, W. G. "Da Poliarquia à oligarquia? Eleições e demanda por renovação parlamentar". Sociedade e Estado, vol.12, n²1, jan.-jun 1997.

“Eleição, representação, política substantiva”. Dados, vol.8, 1971. 
. Crise e castigo: partidos e generais na política brasileira. São Paulo:

Vértice, 1987.

Votos e partidos. Almanaque de dados eleitorais (Brasil e outros países).

Rio de Janeiro: Fundação Getúlio Vargas, 2002.

. O Cálculo do conflito. Belo Horizonte: UFMG, 2003.

SCHMITT, R. A. "Migração Partidária e Reeleição na Câmara dos Deputados". Novos Estudos Cebrap, São Paulo, vol.54, 1999.

SOARES, G. A. D. e D'ARAÚJO, M. C. "A imprensa, os mitos, e os votos nas eleições de 1990". Revista Brasileira de Estudos Políticos, vol76, 1993.

Alvaro Barreto - albarret.sul@terra.com.br

Recebido para publicação em maio de 2007. Aprovado para publicação em setembro de 2007. 